\title{
Kreative Erinnerung und erinnerte Sache - der gordische Knoten des Johannesevangeliums
}

Esther Straub

«Kreative Erinnerung. Relecture und Auslegung im Johannesevangelium»: So lautet der Titel des Aufsatzsammelbands von Jean Zumstein, und dieser Titel ist - wie der vorangehende Essay in diesem Heft zeigt - Programm. In zweierlei Hinsicht:

Einerseits thematisiert der Autor Relectureprozesse, die er auf verschiedensten Ebenen des Johannesevangeliums und der Johannesbriefe entdeckt. Er versteht das Evangelium als eine Strategie des Glaubens, die darauf aus ist, einen elementaren Glauben weiterzudenken und zu vertiefen. Interpretationsbewegungen durchziehen das gesamte johanneische Korpus. Zumstein identifiziert ein permanentes theologisches Suchen, ein Rekontextualisieren, zuweilen auch ein Regulieren. Die Sache des Textes, so könnte man sagen, ist in ständiger Bewegung, wird vertieft, neu ausgelegt, kreativ erinnert.

Neben dieser breiten Entfaltung des Relectureprozesses finden sich in Zumsteins Aufsätzen jedoch auch immer wieder Passagen, die von der Sache selbst sprechen, sie gewissermassen arretieren - allerdings stets im Bewusstsein, dass auch diese Arretierung eine Relecture ist, eine kreative Erinnerung dessen, wovon im Johannesevangelium die Rede ist. Der Titel bleibt Programm.

Die Darlegung des Relectureprozesses und die Entfaltung der Sache des Textes bilden zwei Stränge, die eng miteinander verknüpft sind. Streckenweise lässt sich dieser Knoten gar kaum lösen. Denn Zumstein versteht den johanneischen Relectureprozess nicht nur als ein gewöhnliches Phänomen der Tradierung von Texten, als eine Bewegung, in die hinein die Sache des Textes gezogen wird, sondern auch als ein Stück der Sache selbst. Das Johannesevangelium reflektiert die Erinnerung, thematisiert auf einer Metaebene den Tradierungsprozess, dem es selbst unterworfen ist, und stellt dessen Handlungsträger vor. Es macht die Relecture zu seiner eigenen Sache - oder genauer: Es verankert sie in seiner eigenen Sache - oder noch genauer: Die Sache des Textes fordert den Text zur Relecture und zur kreativen Erinnerung heraus.

Im folgenden versuche ich nachzuzeichnen, wie und wo Zumstein diese beiden Stränge der Relecture und der Sache des Textes entknotet. Wo wird im Johannnesevangelium die Relecture in der Sache verankert? 
Die Sache des Textes oder «die grundlegende Fragestellung des Evangeliums» - so schreibt der Autor (207) ${ }^{\star}$ - sei christologisch. Es gehe dem Evangelium darum, die «volle Erkenntnis der wahren Identität Christi» zu ermöglichen. "Der Mensch Jesus ist niemand anders als Gott selbst inmitten der Welt» (95). «Dédoublement de Dieu» nennt er mit Léon-Dufour diesen Sachverhalt, wie jetzt, in der deutschen Übersetzung, nur noch in den Fussnoten nachzulesen ist. Andere Ausdrücke, die sich auf denselben Sachverhalt beziehen, lassen sich besser übersetzen: «hohe Christologie», «Paradox», «konsequente Geschichtlichkeit der Offenbarung».

Der Prolog vollzieht als theologische Schwelle zum Evangelium «den Übergang vom Mythos zur Geschichte, von der unerreichbaren und unbeschreibbaren göttlichen Wirklichkeit zur Wirklichkeit der Welt, vom Unvordenklichen zum Erinnerbaren. Die Dynamik des Prologs macht aus dem göttlichen Logos einen Menschen im Fleisch, aus dem transzendenten Wort ein Gesicht, das betrachtet werden kann, aus dem Präexistenten einen konkreten, greifbaren Menschen» (97).

Im Artikel «Das Johannesevangelium: Eine Strategie des Glaubens» zeigt sich eine erste Spur, wie dieser christologische Strang mit dem Strang der Relecture verknüpft sein könnte. Da heisst es: «Fordert der erste Teil des Evangeliums den Leser auf, die grundlegende Identität des Sohnes [...] zu entdecken, so stellt der zweite Teil die Frage nach der Relevanz dieser Identität in der nachösterlichen Situation" (40). Der Knoten lockert sich.

Dass dem zweiten Teil des Evangeliums die Funktion zukommt, die Relevanz der irdischen Geschichte Jesu für die nachösterliche Gemeinde aufzuzeigen, legt Zumstein vor allem anhand der Abschiedsreden dar, interpretieren doch diese den Tod Jesu als einen produktiven Tod (121). Das irdische Schicksal des Offenbarers muss zu Ende gehen, denn erst derWeggang des Gesandten lässt die Bedeutung seines Schicksals vollends erfassen und dessen wahre Tragweite ermessen. Ist die Zeit der Offenbarung die Zeit des irdischen Jesus, so die nachösterliche Zeit die Zeit des Parakleten, der die Offenbarung fortwährend in der Gegenwart aktualisiert, erinnert. Der Offenbarer begegnet dem nachösterlichen Jünger in der Gestalt eines Wortes, das sich vervielfacht und austeilt. Die physische Abwesenheit des Offenbarers wird so transzendiert. Die hinterlassene Lücke ermöglicht eine Rückkehr in Fülle.

Der Knoten scheint gelöst: Der Ort, wo der christologische Strang mit dem Strang der Relecture verknüpft wird, ist Jesu Tod, seine 
Rückkehr zum Vater, sein Weggang aus der Welt. Dieser Weggang schafft die Bedingungen, die Identität Christi in jeder Gegenwart neu und kreativ zu erinnern.

Nun finden sich in Zumsteins Aufsätzen neben diesen Überlegungen zum Tod Jesu auch Passagen, die in der joh Passionsgeschichte noch einen weiteren Knotenpunkt identifizieren: Der Tod Jesu ist nicht nur die Bedingung der nachösterlichen Verkündigung der Inkarnation, sondern er vollendet auch die Inkarnation als solche, er ist ihr konsequenter Höhepunkt, ihr Brennpunkt. Denn der Tod am Kreuz ist es, der die Geschichte des irdischen Jesus als eine radikal menschliche beglaubigt (68). Die christologische These wird differenziert. Nicht einfach der Mensch Gewordene ist Gott selbst inmitten der Welt, sondern der Gekreuzigte (96). Das Paradox der Inkarnation wird als Paradox des Kreuzes gesteigert: Das Königtum Christi zeigt sich in der Gestalt eines verhöhnten und verworfenen, eines ohnmächtigen Menschen (101/137). Die Stunde der Verherrlichung ist die Stunde des Todes, die Erhöhung geschieht am Kreuz.

Der Tod Jesu verknüpft somit nicht nur den Strang der christologischen Sache und den Strang der Relecture miteinander, sondern bildet zugleich den Knotenpunkt des ersten Strangs. Das Kreuz radikalisiert einerseits die Offenbarung der Identität Christi und schafft andererseits die Bedingungen der Relecture dieser Identität. «Die Passionsgeschichte ist der Kulminations- und Höhepunkt der joh Erzählung. Das Kreuz ist nicht nur der Ort, an dem die Offenbarung zu ihrerVollendung und ihrem Abschluss kommt, sondern auch der Ort, an dem die Bedingungen ihrer nachösterlichen Verkündigung festgelegt werden» (140).

Hier schliesst sich meine kritische Rückfrage an, die an dieser Stelle allerdings nur als skizzenhafte Gegenthese präsentiert werden kann. Der Stellenwert des Kreuzes bildet einen der umstrittensten Punkte der Johannesexegese. Alternativen wie Niedrigkeitstheologie oder Herrlichkeitstheologie, pointierte Inkarnation oder naiver Doketismus, Rechtgläubigkeit oder Ketzerei stehen auf dem Spiel, wenn es darum geht, die johanneische Passionsgeschichte $\mathrm{zu}$ interpretieren. Zumsteins Erörterungen zur Relecture zeigen auf, dass der zweite Buchteil des Johannesevangeliums in erster Linie ein Thema entfaltet, das sich auf einer Metaebene zum engeren christologischen Problem situiert: die Vergegenwärtigung des ergangenen Offenbarungsgeschehens in jeder neuen Zukunft. Es stellt sich die Frage, ob sich der zwei- 
te Buchteil (Joh 13-20) nicht ganz auf dieses Thema beschränkt, d.h. die Zukunft der im ersten Buchteil (Joh 2-12) zur Sprache gekommenen christologischen Identität des irdischen Jesus reflektiert, ohne zusätzlich darauf auszusein, diese Identität in Kontinuität zum ersten Buchteil weiter zu entfalten und zum Kulminationspunkt zu führen. M.E. finden sich im Text zahlreiche Anhaltspunkte, das Kreuz von der Funktion christologischer Offenbarung im engeren Sinne zu entbinden und es dezidiert als Ort zu verstehen, wo die im ersten Teil des Evangeliums erfolgte Offenbarung in Kraft gesetzt wird, wo über ihre Ablehnung gerichtet und ihre zukünftige Relevanz begründet wird, ohne dass sie selbst noch einmal oder gar in radikalisierter Form zur Entfaltung kommt. Kurz: Der gordische Knoten des Johannesevangeliums liesse sich in klassischer Weise mit einem Schwertstreich lösen, der das Evangelium nach Joh 12 in zwei Stränge trennt:Während der erste Strang (Joh 2-12) die Christologie im engeren Sinne entfaltet, reflektiert der zweite Strang (Joh 13-20) die Eschatologie. Welche Tragweite der konsequenten Ausführung dieses Schwertstreichs zukommt, müsste sorgfailtig geprüft werden. Allerdings ist sich die Autorin bewusst, dass Schwertstreiche dem Wesen eines Knotens nicht in jeder Hinsicht gerecht werden und dass sie nicht selten von der ungeduldigen und missverstehenden Haltung ihrer Handlungsträger zeugen.

* Die in Klammern angegebenen Seitenzahlen beziehen sich auf den Aufsatzband: Jean Zumstein, Kreative Erinnerung. Relecture und Auslegung im Johannesevangelium, Zürich 1999.

— Esther Straub ist Assistentin am Lehrstuhl für Neutestamentliche Wissenschaft von Professor Dr. Jean Zumstein. 